\title{
MOBILIZAÇÃO DO SOLO, VELOCIDADE DE INFILTRAÇÃO DE ÁGUA E TAXA DE COBERTURA DO SOLO NA GRAMA ESMERALDA, SOB MANEJOS MECANIZADOS
}

\author{
Alessandro José Marques Santos ${ }^{1}$, Roberto Lyra Villas Bôas ${ }^{2}$, Clarice Backes ${ }^{3}$, Leandro \\ José Grava de Godoy ${ }^{4}$ \& Diógenes Martins Bardiviesso 5
}

\begin{abstract}
RESUMO: A compactação excessiva do solo, observada em sistemas de produção de gramas, afeta as características físicas do solo, e pode influenciar na infiltração de água no solo e consequentemente na taxa de cobertura do solo pela grama e tempo de formação do tapete. Para minimizar os efeitos desta compactação são utilizados, por alguns produtores, equipamentos de preparo do solo. Estes equipamentos devem mobilizar o solo de forma superficial de modo a não causar rugosidade excessiva, que pode reduzir o rendimento da área pela quebra do tapete no momento da colheita ou transporte. Dessa forma, objetivou-se com este trabalho avaliar a velocidade de infiltração e a taxa de cobertura em função de manejos mecanizados na cultura da grama esmeralda. O delineamento experimental utilizado foi o de blocos ao acaso, com quatro repetições. Os tratamentos foram constituídos por cinco sequências de preparo do solo: testemunha (sem o uso de equipamentos); uma passada do aerador de solo (1A); duas passadas do aerador (2A); uma passada do escarificador (1E) e uma passada do escarificador e uma do aerador (1E + 1A). Os tratamentos que receberam a passagem de $2 \mathrm{~A}$ e $1 \mathrm{E}+1 \mathrm{~A}$ proporcionaram maior velocidade de infiltração básica de água no solo e maior taxa de cobertura do solo pela grama esmeralda. A taxa de cobertura do solo pela grama correlaciona-se positivamente com velocidade de infiltração básica aos 133 e 226 DAP, demonstrando a influência dos manejos utilizados na formação do tapete de grama e no incremento na velocidade de infiltração água. Nas condições deste estudo recomenda-se o uso por duas vezes do aerador do solo ou escarificador + aerador.
\end{abstract}

PALAVRAS-CHAVE: Zoysia japonica, manejo do solo, equipamentos de preparo do solo.

\section{SOIL MOBILIZATION, INFILTRATION RATE OF WATER AND SOIL COVER RATE BY ZOYSIAGRASS CV “ESMERALDA" UNDER DIFFERENT MECHANIZED MANAGEMENTS}

\begin{abstract}
The excessive compaction of the soil observed in sod production systems, affects the physical attributes of the soil, which can influence the water infiltration into the soil and hence the rate of soil cover by turfgrasses and time of the sod production. To minimize the effects of soil compacting, some producers use soil preparation equipment that raises the soil on the surface but does not cause excessive roughness which may harm the quality of the sod. Thus, the aim of the present study was to evaluate the infiltration rate and soil cover rate due to different management mechanized in the zoysiagrass sod production. The experimental design had random plots and four replications. The treatments consisted of five mechanized managements of soil: witness (without the use of equipment); coulter blade disc harrow used once (1CB), coulter blade disc harrow used twice (2CB), surface chisel used once (1C), surface chisel and coulter blade disc harrow used once $(1 \mathrm{C}+1 \mathrm{CB})$. The treatments with $2 \mathrm{CB}$ and $1 \mathrm{C}+1 \mathrm{CB}$ provided greater basic water infiltration speed in the soil and higher rate of soil cover by the turfgrass. The rate of soil cover by turfgrass is positively correlated with water infiltration rate at 133 and 226 DAP, demonstrating the influence of managements used in zoysiagrass sod production and the increment in the infiltration rate of water. Soil preparation utilizing coulter blade disc harrow used twice or surface chisel and coulter blade disc harrow used once is recommended under the conditions this study was done.
\end{abstract}

KEYWORDS: Zoysia japonica, soil management, soil preparation equipment.

\footnotetext{
${ }^{1}$ Universidade Estadual de Goiás. Docente do curso de Zootecnia. Email: alessandro.santos@ueg.br

${ }^{2}$ Faculdade de Ciências Agronômicas. Departamento de Solos e

Recursos Ambientais. E-mail: rlvboas@fca.unesp.br

${ }^{3}$ Universidade Estadual de Goiás. Docente do curso de Zootecnia. Email: clarice.backes@ueg.br
}

\footnotetext{
${ }^{4}$ Universidade Estadual Paulista. Campus Experimental de Registro. Email: legodoy@ registro.unesp.br

${ }^{5}$ Faculdade de Ciências Agronômicas. Doutorando do Departamento de Horticultura. E-mail: bardiviesso@yahoo.com.br
} 


\section{INTRODUÇÃO}

De acordo com Turner (2003) o primeiro objetivo na maioria das culturas, é maximizar a produtividade de maneira econômica, enquanto na produção de grama o objetivo é duplicado: produzir grama de qualidade suficiente para que seja comercializável e produzir tapete que possa ser colhido (que se mantenha inteiro para poder ser transplantado) da maneira mais rápida possível.

Para a obtenção de tapetes inteiros, antes do corte, é realizada a passagem de um rolo compactador em solo úmido com a finalidade de promover pressão na camada superficial. Segundo Brouwer (2004) passar o rolo antes de colher permite cortar tapetes finos com e espessura mais uniforme. No entanto, apesar do benefício promovido no corte, é comum que a compactação ultrapasse a profundidade do limite do tapete, afetando as propriedades físicas do solo e consequentemente o desenvolvimento da grama no próximo ciclo.

Além da compactação excessiva proporcionada pela passagem do rolo, Moraes et al. (2008) citam ainda que o corte dos tapetes de grama proporciona o selamento superficial do solo, principalmente naqueles de textura argilosa ou muito argilosa que são os utilizados para a produção. $\mathrm{O}$ selamento causa restrição à entrada de água no solo, por obstruir poros importantes para o fluxo, principalmente macroporos (GONÇALVES; MORAES, 2012).

Segundo Bertol et al. (2001) em solos intensamente cultivados o surgimento de camadas compactadas determina a diminuição do volume de poros ocupado pelo ar e o aumento na retenção de água. Em decorrência disto, foi observado pelos autores diminuição da taxa de infiltração de água no solo, com consequente aumento das taxas de escoamento superficial.

O processo de infiltração é de importância prática por que, muitas vezes, determina o balanço de água na zona das raízes e o deflúvio superficial, responsável pela erosão hídrica. Assim, o conhecimento do processo e sua relação com as características do solo são de fundamental significância para o eficiente manejo do solo e da água nos cultivos agrícolas (REICHARDT, 1996).

De acordo com Brandão et al. (2006) a infiltração de água no solo depende principalmente de fatores relacionados ao solo, superfície, preparo e manejo do solo, considerando estes como fatores condicionantes dos meios porosos que relaciona-se com o movimento da água no solo e encrostamento superficial. A dinâmica da água no solo também é afetada pelos fatores externos como cobertura do solo e densidade de plantas (LLANILLO et al., 2006).

Com o aumento da taxa de cobertura das gramas pode-se ter maior aproveitamento da água da chuva e também da irrigação, prática utilizada em diversas regiões do país, devido ao balanço hídrico desfavorável. Porém, no início (após o corte dos tapetes) o solo está totalmente descoberto, com restrição à entrada de água, sendo necessária a adoção de práticas mecânicas de preparo para aumentar a infiltração da água no solo e consequentemente a velocidade de taxa de cobertura do solo pela grama.

Santos et al. (2009) ao avaliarem a resistência do solo à penetração logo após o corte de tapetes de grama verificaram resultados médios de compactação de 3,955; 10,$155 ; 9,475$ e 4,990 $\mathrm{MPa}$ nas profundidade de 0-5, 5$10,10-20$ e $20-40 \mathrm{~cm}$, respectivamente. Os autores atribuíram a menor compactação na camada de $0-5 \mathrm{~cm}$ devido a presença de rizomas e raízes que permaneceram no solo após o corte dos tapetes. A camada mais compactada foi a de $5-10 \mathrm{~cm}$ atingindo valor médio de $10.155 \mathrm{kPa}$ ou 10,155 MPa. De acordo com Silva et al. (2002) solos com IC acima de $2000 \mathrm{kPa}$ indicam uma possibilidade de compactação, limitando o crescimento radicular para a maioria das culturas.

Há uma hipótese de que a escarificação do solo minimiza a compactação resultante do corte dos gramados. Esta prática permite manipulação mecânica mínima do solo, mantêm o máximo possível de resíduos na superfície, possibilitando maior infiltração de água, menor dano às unidades de estrutura e maior porosidade do solo, à medida que ocorre maior infiltração da água (MORAES et al., 2008).

A abertura de espaços porosos no solo favorece também o crescimento das raízes da grama nestes pontos, acelerando o fechamento das áreas para o próximo corte dos tapetes. De acordo com Backes et al. (2009), como prática no sistema de produção de grama, os produtores utilizam escarificadores a fim de melhorar também a eficiência da adubação, que é realizada superficialmente.

Com a compactação excessiva dos solos em áreas de produção de grama, o produtor é levado a fabricar equipamentos alternativos com chassis, órgãos ativos de semeadoras, grades, adubadoras, entre outros, para tentar diminuir este problema, visto que não são disponibilizados no mercado equipamentos para este fim (SANTOS et al., 2010).

Dessa forma, objetivou-se com o presente trabalho avaliar a área de solo mobilizada, velocidade de infiltração de água no solo e a taxa de cobertura do solo pela grama esmeralda em função de manejos mecanizados.

\section{MATERIAL E MÉTODOS}

O experimento foi instalado e conduzido em propriedade comercial de produção de grama no município de TatuíSP. As coordenadas geográficas da área são: $\mathrm{S}$ e 47 59'39' 'O de Greenwich e altitude média de $636 \mathrm{~m}$. A área é utilizada para o corte de tapete de gramas há 28 anos, sem renovação. O início do experimento com os preparos do solo ocorreram 15 dias após a colheita dos tapetes (18 de janeiro de 2010).

O solo onde foi instalado o experimento é classificado como Latossolo Vermelho distrófico (LVd) A moderado 
de textura argilosa, suavemente ondulado, de acordo com o mapa pedológico do Estado de São Paulo (OLIVEIRA et al., 1999). De acordo com o resultado da análise o solo possuía as seguintes características químicas, antes da instalação do experimento: $\mathrm{pH}$ $\left(\mathrm{CaCl}_{2}\right)$ de 5,2; $26 \mathrm{~g} \mathrm{dm}^{-3}$ de M.O.; $9 \mathrm{mg} \mathrm{dm}^{-3}$ de P (resina); 30; 0,6; 32 e 13 mmol $_{\mathrm{c}} \mathrm{dm}^{-3}$ de H+Al, K, Ca e $\mathrm{Mg}$, respectivamente; saturação por bases (V) de $61 \%$. A composição granulométrica do solo foi de 294, 499 e $207 \mathrm{~g} \mathrm{~kg}^{-1}$ de areia, argila e silte, respectivamente. A densidade do solo inicial era de 1,42 e $1,54 \mathrm{~kg} \mathrm{dm}^{-3}$, nas camadas de $0-10$ e $10-20 \mathrm{~cm}$, respectivamente, determinada pelo método do torrão parafinado, descrito na metodologia da Embrapa (1997).
Os dados de precipitação pluvial $(\mathrm{mm})$, temperatura máxima e mínima absoluta e temperatura máxima, mínima e média mensal do ar (graus Celsius), no município de Tatuí, no período compreendido entre a implantação do primeiro ciclo e o final do segundo são apresentados nas Figuras 01 e 02. A precipitação na área apresentou comportamento dentro dos padrões esperados, com inverno com baixa pluviosidade e verão, principalmente em janeiro de 2011, com elevada precipitação (350 mm no mês). A temperatura também mostrou variação ao longo do ano, com baixas temperaturas no inverno, que afetam significativamente o desenvolvimento de gramas como a esmeralda.

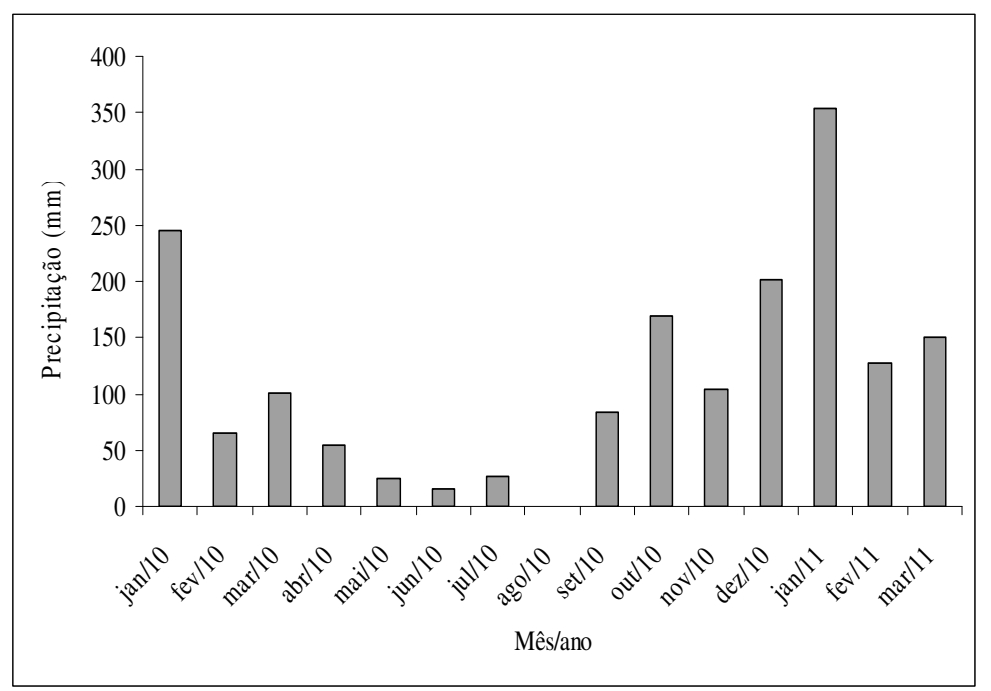

Figura 01 - Precipitação no município de Tatuí, SP, durante o período de janeiro de 2010 a março de 2011.

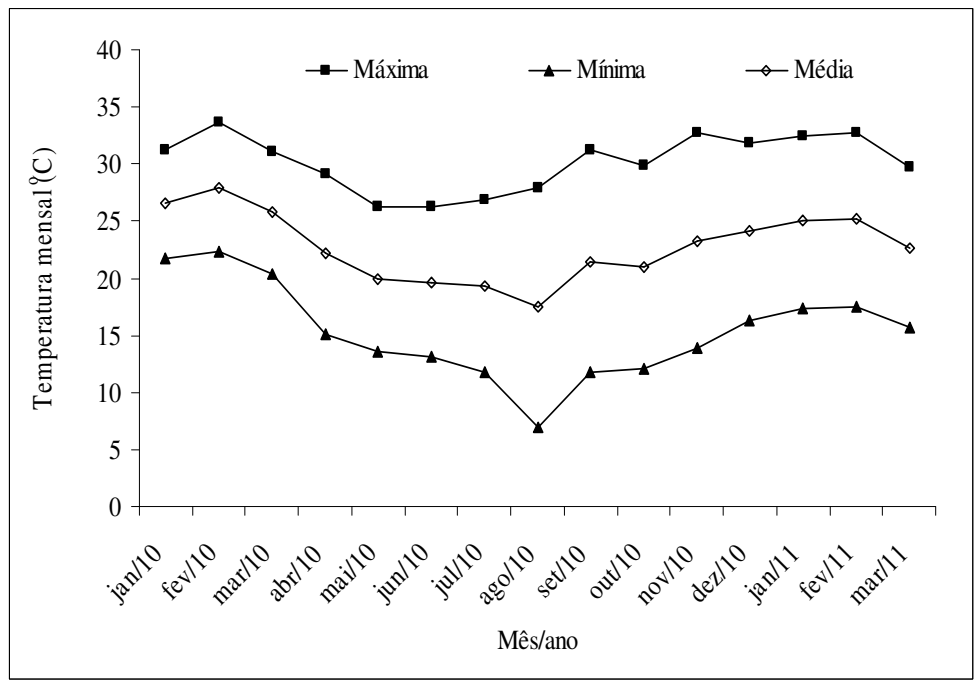

Figura 02 - Temperaturas máxima, mínima e média mensal do ar no município de Tatuí, SP, durante o período de janeiro de 2010 a março de 2011.

Foi utilizada a espécie Zoysia japonica Steud. conhecida, popularmente, como grama esmeralda. Esta espécie é rizomatosa e estolonífera, portanto, pode ser colhida em área total, visto que após a colheita ficam rizomas subsuperficiais capazes de rebrotar para cobrir novamente o solo. Foi escolhida esta espécie pela sua 
importância econômica, pois de acordo com Zanon e Pires (2010) das gramas cultivadas no Brasil, $74 \%$ é esmeralda.

O delineamento experimental utilizado foi o de blocos ao acaso, com quatro repetições. Os tratamentos foram constituídos por cinco preparos do solo: 1) testemunha (sem o uso de equipamentos); 2) uma passada do aerador de solo (1A); 3) duas passadas do aerador (2A); 4) uma passada do escarificador (1E) e 5) uma passada do escarificador e uma do aerador $(1 \mathrm{E}+1 \mathrm{~A})$. As parcelas experimentais mediam $10 \times 6 \mathrm{~m}$ e foram separadas uma das outras dentro de um mesmo bloco, por $5 \mathrm{~m}$, espaço este utilizado para facilitar manobras do trator e equipamentos. Do mesmo modo, entre blocos, foi mantido espaçamento de 3 metros.

Os tratamentos foram instalados em janeiro de 2010, aproximadamente 15 dias após a colheita dos tapetes anteriores.

Foram utilizados dois equipamentos de preparo do solo. A "estrelinha" também conhecida como aerador de solo, que consiste, geralmente, de chassi de grade intermediária de arrasto com secções paralelas, portando 20 discos planos de 16 polegadas com recortes em formato de estrela de 8 pontas, com espaçamento entre discos de $15 \mathrm{~cm}$. O escarificador superficial possui sistema de acoplamento montado, com cinco hastes e apresenta como características espaçamento entre hastes de $40 \mathrm{~cm}$ e largura da ponteira de aproximadamente 2 $\mathrm{cm}$, com profundidade máxima de $14 \mathrm{~cm}$.

A cultura da grama foi conduzida de acordo com os manejos convencionais do produtor (adubação, controle de insetos pragas e plantas daninhas, roçadas, irrigação). A adubação inicial foi realizada aos 22 dias após o corte dos tapetes anteriores (25/01/2010), com a aplicação de $800 \mathrm{~kg} \mathrm{ha}^{-1}$ do fertilizante misto (mistura de grânulos) de fórmula 04-14-08, totalizando 32, 117 e $64 \mathrm{~kg} \mathrm{ha}^{-1}$ de N, $\mathrm{P}_{2} \mathrm{O}_{5}$ e $\mathrm{K}_{2} \mathrm{O}$, respectivamente. Todo o $\mathrm{P}$ (fósforo) foi adicionado neste período. $\mathrm{O}$ restante do $\mathrm{N}$ (nitrogênio) foi aplicado em cobertura, parcelado em três vezes, e o K (potássio) em mais uma vez. A adubação total aplicada durante o ciclo foi de $375 \mathrm{~kg} \mathrm{ha}^{-1}$ de $\mathrm{N}, 112 \mathrm{~kg} \mathrm{ha}^{-1}$ de $\mathrm{P}_{2} \mathrm{O}_{5}$ e $157 \mathrm{~kg} \mathrm{ha}^{-1}$ de $\mathrm{K}_{2} \mathrm{O}$. A fonte de $\mathrm{N}$ utilizada foi o sulfato de amônio aplicado aos 60 (04/03/2010), 115 (28/04/2010) e $241(01 / 09 / 2010)$ dias após o corte dos tapetes, sendo a área irrigada até 24 horas após a aplicação. A fonte de $\mathrm{K}$ foi o cloreto de potássio $(\mathrm{KCl})$ aos $115(28 / 04 / 2010)$ dias após o corte do tapete anterior.

Para a determinação da área de solo mobilizada pelos equipamentos utilizou-se um perfilômetro de madeira com 40 hastes graduadas em centímetros, espaçadas a cada $0,05 \mathrm{~m}$, instalado sobre marcadores de madeira. Efetuou-se o levantamento do perfil da superficial natural (antes do preparo) e de fundo (após os preparos), conforme a metodologia descrita por Lanças (1987). Após a obtenção dos dados dos perfis estes foram tabulados, plotados e calculados no programa Microsoft Excel, obtendo a área de solo mobilizado.
A velocidade de infiltração básica (VIB) foi determinada, utilizando-se o método do infiltrômetro de anéis concêntricos, composto por um anel metálico maior, com $40 \mathrm{~cm}$ de diâmetro, um anel menor, com 20 $\mathrm{cm}$ de diâmetro e uma proveta graduada para leitura da quantidade de água infiltrada.

As medidas do volume de água infiltrada foram feitas no anel interno, pois o anel externo tem a finalidade de bordadura, impedindo que a infiltração se processe no sentido lateral do solo. Mediu-se o volume aplicado em intervalos fixos de tempo, durante o período médio de duas horas. A infiltração da água no solo foi determinada aos 43, 133 e 226 dias após o corte do tapete anterior (DAP).

A taxa de cobertura do solo (TCS) pela grama foi avaliada por meio da análise de imagem digital. As imagens digitais foram obtidas por uma câmera digital Sony ${ }^{\circledR}$ DSC-W30 6.0 mega pixels fixada na extremidade de uma estrutura na forma de um " $L$ " invertido para que as imagens fossem captadas paralelamente à superfície do gramado, sempre na mesma altura $(1,6 \mathrm{~m})$. As imagens foram descarregadas em um computador e cada uma dessas figuras foi analisada no programa Corel Photo Paint v. 12 (COREL CORPORATION, 2003) que permite contar o número de pontos (pixels) de uma determinada cor (e suas tonalidades) existente na imagem. Selecionando o número de pixels das cores verdes e palha na imagem, foi possível determinar a porcentagem do solo coberto pela grama conforme metodologia citada por Godoy (2005). A TCS pela grama esmeralda foi determinada aos 43, 87, 133, 178, 226, 315 e 365 DAP.

Os resultados foram submetidos à análise de variância utilizando-se o programa "SISVAR", versão 4.2 (FERREIRA, 2003). As médias dos tratamentos foram comparadas por meio da aplicação do teste de Tukey ao nível de $5 \%$ de probabilidade. Para o atributo velocidade de infiltração de água no solo, as épocas de avaliação foram consideradas como tratamentos, como se fossem parcelas subdivididas no tempo. Foram testadas as correlações lineares de Pearson pelo teste $\mathrm{T}$ entre as os atributos velocidade de infiltração do solo e taxa de cobertura do solo pela grama, em três datas $(43,133$ e 226 DAP).

\section{RESULTADOS E DISCUSSÃO}

\subsection{Mobilização do solo}

Verifica-se que para área de solo mobilizada houve diferença significativa entre os preparos, com maior mobilização quando realizada duas passagem do aerador de solo (2A) na área (Tabela 01 ). O resultado mais expressivo para duas passagens do aerador (2A) pode ser justificado pela mobilização mais uniforme na parcela experimental, proporcionada pelo espaçamento reduzido $(0,15 \mathrm{~m})$ entre os discos (estrelas de oito pontas), além de que este foi passado na mesma área por duas vezes seguidas.

A passagem do escarificador resultou em menor área de solo mobilizada, em função do maior espaçamento entre 
as hastes $(0,40 \mathrm{~m})$, resultando em pequenas áreas trabalhadas. Embora as hastes mobilizem menor área de solo, há possibilidade dos equipamentos promoverem o corte e rompimento de raízes e rizomas, enfraquecendo a resistência dos tapetes, uma vez que a rede formada por estas estruturas dificulta o rompimento dos tapetes na colheita. Backes et al. (2009) verificaram menor resistência dos tapetes quando utilizaram três passadas com a "estrelinha" no início do ciclo e atribuíram este efeito ao corte das raízes e rizomas no momento do preparo.

Tabela 01 - Área de solo mobilizada (em relação ao perfilômetro) pelos equipamentos nos diferentes preparos do solo para produção de grama esmeralda (Tatuí, $S P, 2010)$.

\begin{tabular}{cc}
\hline Tratamentos & Área de solo mobilizada \\
\hline & $----\mathbf{c m}^{2}-\cdots----$ \\
$1 \mathrm{~A}$ & $296 \mathrm{~b}$ \\
$2 \mathrm{~A}$ & $472 \mathrm{a}$ \\
$1 \mathrm{E}$ & $96 \mathrm{c}$ \\
$1 \mathrm{E}+1 \mathrm{~A}$ & $366 \mathrm{~b}$ \\
\hline CV\% & 13,92 \\
\hline
\end{tabular}

Letras iguais na coluna não diferem entre si pelo teste de Tukey a $5 \%$ de probabilidade. $1 \mathrm{~A}$ - uma passada do aerador de solo; 2A - duas passadas do aerador; $1 \mathrm{E}$ - uma passada do escarificador; $1 \mathrm{E}+1 \mathrm{~A}$ - uma passada do escarificador e uma do aerador.

No sistema de produção de gramas a mobilização do solo deve ser mínima, pois existe a necessidade de se manter o nivelamento da área para que não ocorram dificuldades na colheita dos tapetes. Caso haja grande movimentação ou maior rugosidade poderá ocorrer desuniformidade de espessura no momento da colheita, o que promoverá variações na sua resistência, e queda no rendimento por área devido a quebra de tapetes que não prestam para ser comercializados.

A área de produção de gramas deve ser nivelada para que possa ser realizada a colheita mecânica, e no caso da espécie estudada, a colheita é realizada em área total, ficando os rizomas responsáveis pela regeneração e formação de um novo tapete.

\subsection{Taxa de cobertura do solo pela grama}

A taxa de cobertura do solo pela grama não foi influenciada pelos tratamentos apenas na primeira época de avaliação (43 DAP) (Tabela 02). Verificou-se que aos 87 e 133 DAP o tratamento $1 \mathrm{~A}$ e testemunha proporcionaram taxas de cobertura menores que $\mathrm{O}$ tratamento $2 \mathrm{~A}$.

O uso do escarificador (1E) sozinho ou com o aerador $(1 \mathrm{E}+1 \mathrm{~A})$ proporcionou maior taxa de cobertura que o tratamento testemunha, entretanto, não diferiram da taxa do tratamento com uma única passada da estrelinha. Nota-se que praticamente os valores da taxa de cobertura aos 87 e aos 133 DAP foram os mesmos, pois foram determinados em meados de abril e junho, quando as temperaturas reduziram (Figura 01) reduzindo a taxa de crescimento da grama esmeralda (GODOY et al., 2007).

Tabela 02 - Taxa de cobertura do solo pela grama esmeralda em função dos diferentes preparos do solo aos 43, 87, 133, 178, 226, 315 e 365 dias após o preparo do solo - DAP (Tatuí, SP, 2010).

\begin{tabular}{cccccccc}
\hline \multirow{2}{*}{ Tratamentos } & \multicolumn{7}{c}{ Taxa de cobertura do solo pela grama } \\
\cline { 2 - 7 } & \multicolumn{7}{c}{ Épocas de avaliação (DAP) } \\
\cline { 2 - 7 } & $\mathbf{4 3}$ & $\mathbf{8 7}$ & $\mathbf{1 3 3}$ & $\mathbf{1 7 8}$ & $\mathbf{2 2 6}$ & $\mathbf{3 1 5}$ & $\mathbf{3 6 5}$ \\
\hline \multirow{2}{*}{ Testemunha } & $26,7 \mathrm{a}$ & $36,1 \mathrm{c}$ & $37,3 \mathrm{c}$ & $46,6 \mathrm{~b}$ & $47,6 \mathrm{~b}$ & $85,5 \mathrm{~b}$ & $98,4 \mathrm{~b}$ \\
$1 \mathrm{~A}$ & $27,6 \mathrm{a}$ & $37,6 \mathrm{bc}$ & $38,6 \mathrm{bc}$ & $46,5 \mathrm{~b}$ & $49,5 \mathrm{~b}$ & $86,3 \mathrm{ab}$ & $98,4 \mathrm{~b}$ \\
2A & $25,9 \mathrm{a}$ & $42,2 \mathrm{a}$ & $43,5 \mathrm{a}$ & $50,6 \mathrm{a}$ & $55,4 \mathrm{a}$ & $90,4 \mathrm{a}$ & $99,4 \mathrm{a}$ \\
$1 \mathrm{E}$ & $25,8 \mathrm{a}$ & $41,0 \mathrm{ab}$ & $42,3 \mathrm{ab}$ & $47,9 \mathrm{ab}$ & $54,1 \mathrm{a}$ & $88,6 \mathrm{ab}$ & $98,6 \mathrm{~b}$ \\
$1 \mathrm{E}+1 \mathrm{~A}$ & $25,9 \mathrm{a}$ & $41,0 \mathrm{ab}$ & $42,3 \mathrm{ab}$ & $50,1 \mathrm{a}$ & $54,1 \mathrm{a}$ & $90,4 \mathrm{a}$ & $99,5 \mathrm{a}$ \\
\hline CV\% & & \multicolumn{7}{c}{3,87} & & &
\end{tabular}

Letras iguais na coluna não diferem entre si pelo teste de Tukey a 5\% de probabilidade. 1A - uma passada do aerador de solo; $2 \mathrm{~A}$ duas passadas do aerador; $1 \mathrm{E}$ - uma passada do escarificador; $1 \mathrm{E}+1 \mathrm{~A}$ - uma passada do escarificador e uma do aerador.

Aos 178 DAP, observou-se que as taxas de cobertura nos tratamentos $2 \mathrm{~A}$ e $1 \mathrm{E}+1 \mathrm{~A}$ foram maiores que nos tratamentos testemunha e $1 \mathrm{~A}$, mas não diferiram da taxa proporcionada por uma única passada do escarificador (1E). Aos 226 DAP os tratamentos $2 \mathrm{E}, 1 \mathrm{E}$ e $1 \mathrm{E}+1 \mathrm{~A}$ proporcionaram taxas de cobertura do solo maiores, diferenciando dos tratamentos testemunha e $1 \mathrm{~A}$. Evidencia-se que os maiores incrementos das taxas de cobertura podem estar associados aos tratamentos que proporcionam maior área de solo mobilizado.
O aumento observado a partir dos 226 DAP está relacionado ao início da primavera, devido o aumento na temperatura média e a quantidade de chuvas, além do aumento na quantidade de horas luz por dia (fotoperíodo), que influenciam diretamente no crescimento das gramas. O aumento nas taxas de cobertura observado neste intervalo (226 aos 315 DAP) foi de $38,35,37,34$ e $36 \%$ para a testemunha, 1A, 2A, $1 \mathrm{E}$ e $1 \mathrm{E}+1 \mathrm{~A}$, respectivamente. 
Aos 315 DAP os tratamentos com $2 \mathrm{~A}$ e $1 \mathrm{E}+1 \mathrm{~A}$ proporcionaram as maiores taxas de cobertura do solo, porém diferenciaram apenas da testemunha, que atingiu uma TCS média de 85,5\%. Aos 365 DAP as maiores taxas de cobertura foram obtidas nos tratamentos $2 \mathrm{~A}$ e $1 \mathrm{H}+1 \mathrm{~A}$, com $99,5 \%$ de TCS. Os tratamentos que proporcionaram maiores mobilizações do solo favoreceram o crescimento das gramas e consequentemente aumentaram a velocidade de fechamento dos tapetes formados. O incremento na TCS foi de apenas $1,1 \%$ quando comparado a testemunha. Maiores valores de taxa de cobertura em relação ao tratamento testemunha são observados em experimentos com adubação, principalmente a nitrogenada (GODOY et al., 2012; BACKES et al., 2009; LIMA et al., 2010).

O tempo de formação de tapetes foi maior em relação ao tempo médio de 12 meses para a colheita da grama esmeralda, no Brasil, citado por Pimenta (2003). Este maior período para a produção dos tapetes neste experimento pode ser explicado pelo tempo que vem sendo produzido na área, com aproximadamente 28 anos, sem que ocorra renovação. As condições climáticas também podem ter influenciado, principalmente devido às baixas temperaturas verificadas no ano agrícola (Figura 01). O momento da colheita se dá quando a taxa de cobertura do solo pela grama chega próximo a $100 \%$, o que pode garantir boa formação radicular e consequentemente maior resistência aos tapetes. Com a redução da TCS ocorre também menor resistência dos tapetes e maior perda por área.

Houve aumentos expressivos da taxa de cobertura dos 43 aos 87 DAP e dos 226 aos 315 DAP. No primeiro intervalo (43 aos 87 DAP) os incrementos foram de 9, $16,10,15$ e $15 \%$ para a testemunha, $1 \mathrm{~A}, 2 \mathrm{~A}, 1 \mathrm{E}$ e $1 \mathrm{E}+$ 1A, respectivamente. Este primeiro aumento está relacionado às condições favoráveis do clima, verificadas nesta época. A partir de março as temperaturas começaram a diminuir, reduzindo o crescimento da grama.

\subsection{Velocidade de infiltração básica da água no solo}

A velocidade de infiltração básica (VIB) de água no solo foi influenciada pelos manejos mecanizados e também pelas épocas avaliadas, havendo interação entre as fontes de variação. (Tabela 03). Aos 43, 133 e 226 DAP os tratamentos que promoveram maiores valores de VIB que o tratamento testemunha foram $2 \mathrm{~A}$ e $1 \mathrm{E}+1 \mathrm{~A}$.

Tabela 03 - Velocidade de infiltração básica (VIB) da água no solo em função dos preparos e das épocas de avaliação (43, 133 e 226 dias após o preparo do solo - DAP). (Tatuí, SP, 2010).

\begin{tabular}{|c|c|c|c|}
\hline \multirow{3}{*}{ Tratamentos } & \multicolumn{3}{|c|}{ Velocidade de infiltração básica (VIB) } \\
\hline & \multicolumn{3}{|c|}{ Épocas de avaliação (DAP) } \\
\hline & 43 & 133 & 226 \\
\hline & \multicolumn{3}{|c|}{ 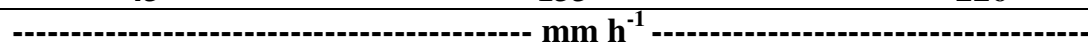 } \\
\hline Testemunha & $20 \mathrm{c} \mathrm{B}$ & $48 \mathrm{c} \mathrm{A}$ & 49 b A \\
\hline $1 \mathrm{~A}$ & $29 \mathrm{bc} \mathrm{B}$ & $52 \mathrm{c} \mathrm{A}$ & $51 \mathrm{~b} \mathrm{~A}$ \\
\hline $2 \mathrm{~A}$ & 56 a B & $93 \mathrm{ab} \mathrm{A}$ & 92 a $\mathrm{A}$ \\
\hline $1 \mathrm{E}$ & $32 \mathrm{bc} \mathrm{B}$ & $70 \mathrm{bc} \mathrm{A}$ & $71 \mathrm{ab} A$ \\
\hline $1 \mathrm{E}+1 \mathrm{~A}$ & $49 \mathrm{ab} \mathrm{B}$ & 104 a A & 93 a A \\
\hline $\mathrm{CV} \%$ & \multicolumn{3}{|c|}{19,16} \\
\hline
\end{tabular}

Letras iguais maiúsculas na linha e minúsculas na coluna não diferem entre si pelo teste de Tukey a 5\% de probabilidade. $1 \mathrm{~A}$ - uma passada do aerador de solo; $2 \mathrm{~A}$ - duas passadas do aerador; $1 \mathrm{E}$ - uma passada do escarificador; $1 \mathrm{E}+1 \mathrm{~A}$ - uma passada do escarificador e uma do aerador.

A maior mobilização do solo (Tabela 01) proporcionou maior infiltração da água no solo quando comparados com os tratamentos que não foram mobilizados e aqueles que receberam apenas uma mobilização. Das características do solo, a capacidade de infiltração é uma das principais, pois reflete a capacidade máxima que o solo tem em permitir a entrada de água no seu interior, sob determinadas condições de compactação, tornandose num dos atributos mais importantes que afetam a irrigação (COSTA et al., 1999), prática de extrema importância na produção de gramas.

O tratamento testemunha, por ter proporcionado maiores valores de densidade do solo e resistência do solo à penetração, quando comparado aos demais tratamentos (SANTOS, 2012), proporcionou baixos valores de VIB principalmente pela compactação superficial que não foi rompida, o que reduz significativamente a infiltração e pode aumentar, dessa forma, o escoamento superficial. Este escorrimento superficial em área de produção de gramas pode causar, entre outros efeitos, o baixo aproveitamento da adubação devido ao escorrimento do adubo, visto que esta prática é realizada na superfície do solo. Backes et al. (2010) e Godoy et al. (2012) observaram baixa eficiência de utilização do $\mathrm{N}$ pela grama esmeralda e Santo Agostinho, em áreas de produção, respectivamente, não absorvendo mais de $32 \%$ do $\mathrm{N}$ aplicado na adubação.

Verifica-se que os maiores valores de VIB foram obtidos na determinação realizada aos 133 DAP $\left(104 \mathrm{~mm} \mathrm{~h}^{-1}\right)$ e 226 DAP $\left(92 \mathrm{~mm} \mathrm{~h}^{-1}\right)$. Tal efeito entre as épocas de amostragem pode ser explicado pela morte e decomposição de raízes que aos 133 DAP geraram 
maiores quantidades de "canais" facilitando a percolação da água.

Fazendo-se estudo de correlações entre a taxa de cobertura do solo (TCS) e a velocidade de infiltração básica (VIB) aos 133 e 226 DAP observa-se uma similaridade nos comportamentos nos dois períodos analisados. Os modelos propostos na Figura 03 demonstram correlação linear positiva onde o aumento da taxa de cobertura de solo proporciona um acréscimo na velocidade de infiltração básica de água.
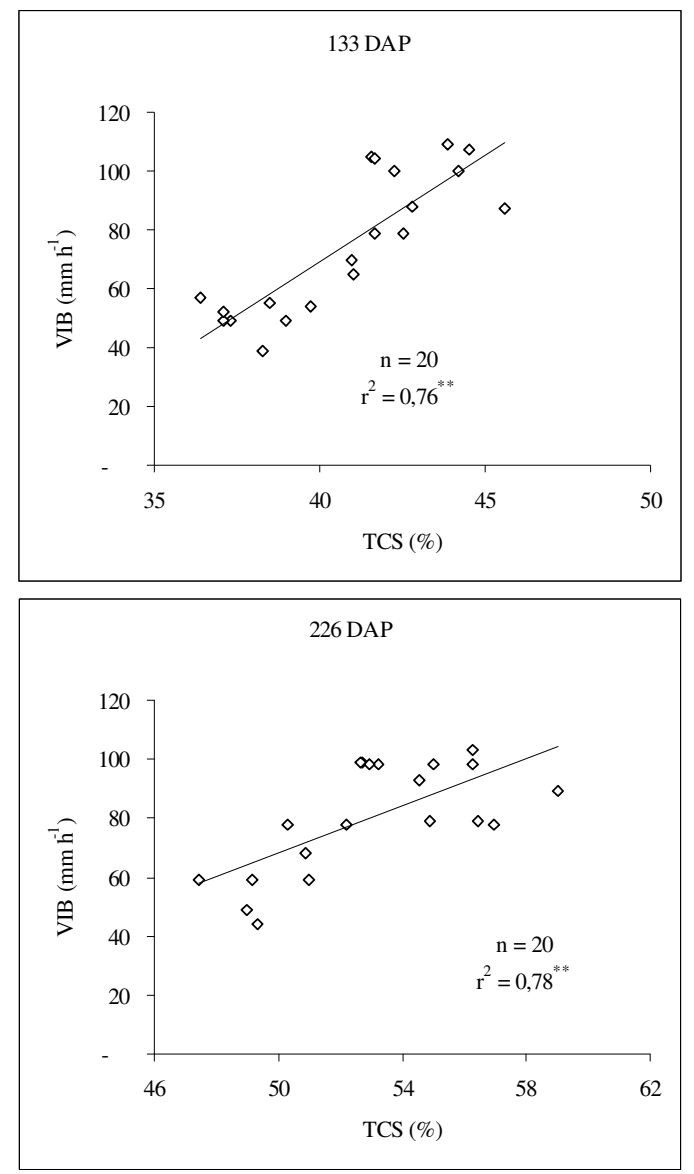

Figura 03 - Correlação da taxa de cobertura do solo (TCS) pela grama esmeralda e velocidade de infiltração básica (VIB) da água no solo, aos 133 e 226 dias após o corte do tapete anterior (Tatuí, $S P, 2010)$.

Segundo Volk et al. (2004) a presença de cobertura vegetal na superfície promove a redução da velocidade de escoamento superficial, aumentando o tempo de oportunidade para infiltração, devido ao aumento da rugosidade hidráulica do percurso ao longo do qual ocorre o escoamento.

De acordo com Bernardo et al. (2005) valores de VIB maior que $30 \mathrm{~mm} \mathrm{~h}^{-1}$ são considerados altos. Valores menores que $30 \mathrm{~mm} \mathrm{~h}^{-1}$ foram obtidos apenas na testemunha e quando realizada a passagem da estrelinha na primeira avaliação realizada. Mesmo sendo um Latossolo, de textura argilosa, este não foi fator limitante à capacidade de infiltração. De acordo com Costa et al.
(1999) a estrutura granular apresentada por este tipo de solo favorece o processo de infiltração.

\section{CONCLUSÃO}

$\checkmark$ Os tratamentos que receberam duas passagens do aerador do solo ou uma passada do escarificador mais uma passagem com o aerador proporcionaram maior velocidade de infiltração básica de água no solo e maior taxa de cobertura do solo pela grama esmeralda;

$\checkmark$ A taxa de cobertura do solo pela grama correlaciona-se positivamente com velocidade de infiltração básica aos 133 e 226 DAP, demonstrando a influência dos manejos utilizados na formação do tapete de grama e no incremento na velocidade de infiltração água;

$\checkmark$ Para o preparo do solo recomenda-se o uso por duas vezes do aerador do solo ou pode-se optar por uma vez o escarificador e em sequência o aerador.

\section{REFERÊNCIAS}

BACKES, C. et al. Uso de lodo de esgoto na produção de tapetes de grama esmeralda. Ciência Rural, Santa Maria, v. 39, n. 4, p. 1045-1050, 2009.

BACKES, C. et al. Produção, acúmulo e exportação de nutrientes em grama esmeralda adubada com lodo de esgoto. Bragantia, Campinas, v. 69, n. 2, p. 413-422, 2010 .

BERNARDO, S.; SOARES, A. A.; MANTOVANI, E. C. Manual de irrigação. 7. ed. Viçosa: UFV, 2005. 611 p.

BERTOL, I. et al. Propriedades físicas de um Cambissolo Húmico afetadas pelo tipo de manejo do solo. Scientia Agricola, Piracicaba, v. 58, n. 3, p. 555$560,2001$.

BRANDÃO, V. S. et al. Infiltração de água no solo, Viçosa, MG: UFV, 2006. 47 p.

BROUWER, G. J. Máquinas para produção de gramas. In: SIGRA SIMPÓSIO SOBRE GRAMADOS MANEJO DE GRAMAS NA PRODUÇÃO E EM GRAMADOS FORMADOS, 2., 2004, Botucatu. Anais... Botucatu: FCA/Unesp, 2004. 1 CD-ROM.

\section{COREL CORPORATION. Corel photo paint. Version} 12.Ottawa, 2003.

COSTA, E. L. et al. Infiltração de água em solo, determinada por simulador de chuvas e pelo método dos anéis. Revista Brasileira de Engenharia Agrícola e Ambiental, Campina Grande, v. 3, n. 2, p. 131-134, 1999. 
EMBRAPA. Manual de métodos de análise de solo. 2. ed. Rio de Janeiro: Embrapa Solos, 1997. 212 p.

FERREIRA, D. F. Sisvar. Versão 4.2. Lavras: UFLA, 2003.

GODOY, L. J. G. Adubação nitrogenada para produção de tapetes de grama santo agostinho e esmeralda. 2005. 106 p. Tese (Doutorado em Agronomia/Agricultura)-Faculdade de Ciências Agronômicas, Universidade Estadual Paulista, Botucatu, 2005.

GODOY, L. J. G. et al. Doses de nitrogênio e potássio na produção de grama esmeralda. Ciência e Agrotecnologia, Lavras, v. 31, n. 5, p. 1326-1332, 2007.

GODOY, L. G.; VILLAS BOAS, R. L.; BACKES, C. Produção de tapetes de grama Santo Agostinho submetida a doses de nitrogênio. Semina: Ciências Agrárias, Londrina, v. 33, p. 1705-1718, 2012.

GONÇALVES, F. C.; MORAES, M. H. Porosidade e infiltração de água do solo sob diferentes sistemas de manejo. Irriga, Botucatu, v. 17, n. 3, p. 337-345, 2012.

LANÇAS, K. P. Subsolador: desempenho em função de formas geométricas de hastes, tipos de ponteiras e velocidade de deslocamento. 1987. 112 f. Dissertação (Mestrado em Agronomia/Energia na Agricultura)Faculdade de Ciências Agronômicas, Universidade Estadual Paulista, Botucatu, 1987.

LIMA, C. P. et al. Bermuda grass sod production as related to nitrogen rates. Revista Brasileira de Ciência do Solo, Viçosa, MG, v. 34, p. 371-377, 2010.

LLANILLO, R. F. et al. Evolução de propriedades físicas do solo em função dos sistemas de manejo em culturas anuais. Semina: Ciências Agrárias, Londrina, v. 27, n. 2, p. 205-220, 2006.

MORAES, M. H.; CORÁ, J. E.; ALMEIDA. A. B. Compactação em gramados: como avaliar e propostas para minimizar o problema. In: VILLAS BÔAS, R. L. et al. Tópicos atuais em gramados I. Botucatu: Faculdade de Ciências Agronômicas, 2008. 205 p.

OLIVEIRA, J. B. et al. Mapa pedológico do Estado de São Paulo. Campinas: Instituto Agronômico, 1999. 64 p.

PIMENTA, C. H. Produção de gramas. In: SIMPÓSIO SOBRE GRAMADOS - PRODUÇÃO IMPLANTAÇÃO E MANUTENÇÃO, 1., 2003, Botucatu. Anais... Botucatu: Faculdade de Ciências Agronômicas, Universidade Estadual Paulista, 2003. 1 CD-ROM.

REICHARDT, K. Infiltração da água no solo. In: REICHARDT, K. Dinâmica da matéria e da energia em ecossistemas. 2. ed. Piracicaba: Escola Superior de Agricultura Luiz de Queiroz, 1996. p. 317-352.
SANTOS, A. J. M. Características físicas do solo e produção de tapetes de grama esmeralda em função de manejos mecanizados. 2012. $71 \mathrm{f}$. Tese (Doutorado em Agronomia/Energia na Agricultura)-Faculdade de Ciências Agronômicas, Universidade Estadual Paulista, Botucatu, 2012.

SANTOS, A. J. M. et al. Equipamentos para descompactação superficial do solo: estudo de casos. In: GODOY, L. J. G. et al. Tópicos atuais em gramados II. Botucatu: FEPAF, 2010. 205 p.

SANTOS, A. J. M. et al. Características químicas e físicas de um solo após a colheita de tapetes de grama esmeralda adubada com lodo de esgoto. Revista Eletrônica de Agronomia, Garça, v. 16, n. 2, p. 21-30, 2009.

SILVA, A. P.; TORMENA, C. A.; IMHOFF, S. Intervalo hídrico ótimo. In: MORAES, M. H.; MÜLLER, M. M. L.; FOLONI, J. S. S. Qualidade física do solo: métodos de estudo-sistemas de preparo e manejo do solo. Jaboticabal: Funep, 2002, p. 1-18.

TURNER, T. R. Nutrient management guidelines for sod production in Maryland. College Park: University of Maryland, 2003. (Turfgrass Technical Update, T114). Disponível em: http://msa.maryland.gov/megafile/msa/speccol/sc5300/sc 5339/000113/003000/003072/unrestricted/20066421e005.pdf. Acesso em: 15 set. 2014.

VOLK, L. B. S.; COGO, N. P.; STRECK, E. V. Erosão hídrica influenciada por condições de superfície e subsuperfície do solo resultantes de seu manejo, na ausência de cobertura vegetal. Revista Brasileira de Ciência do Solo, Viçosa, v. 28, n. 4, p. 763-774, 2004.

ZANON, M.; PIRES, E. C. Situação atual e perspectivas do mercado de grama no Brasil. In: GODOY, L. J. G. et al. Tópicos atuais em gramados II. Botucatu: Faculdade de Ciências Agronômicas, Universidade Estadual Paulista, 2010. 205 p. 